\title{
Interannual-Interdecadal Variation in Large-Scale Atmospheric Circulation and Extremely Wet and Dry Summers in China/Japan during 1951-2000 Part I: Spatial Patterns
}

\author{
Hengyi WENG \\ Center for Climate System Research, University of Tokyo, Tokyo, Japan \\ LASG, Institute of Atmospheric Physics, Chinese Academy of Sciences, Beijing, China \\ Akimasa SUMI, Yukari N. TAKAYABU, Masahide KIMOTO \\ Center for Climate System Research, University of Tokyo, Tokyo, Japan \\ and \\ Chongyin LI \\ LASG, Institute of Atmospheric Physics, Chinese Academy of Sciences, Beijing, China \\ (Manuscript received 4 April 2003, in final form 6 January 2004)
}

\begin{abstract}
This is the first part of a two-part study that seeks links between summer rainfall variability in China/Japan and the large-scale circulation over the East Asia/western Pacific region, in both space and time, for the period of 1951-2000. Part I focuses on the spatial patterns, while Part II on the dominant timescales with which some extremely wet and dry summers in these two countries may have occurred. In this part, we use the singular value decomposition (SVD) method to find the dominant covariance patterns of summer rainfall anomalies over 160 stations in China and 72 stations in Japan, and the regional $500 \mathrm{hPa}$ geopotential height anomaly over $60^{\circ} \mathrm{E}-160^{\circ} \mathrm{W}, 20^{\circ} \mathrm{S}-70^{\circ} \mathrm{N}$. The associated $850 \mathrm{hPa}$ horizontal wind patterns are studied by linear regression against the temporal coefficients of these modes. For a positive temporal coefficient, SVD1 represents a north-south wave pattern: a blocking high over eastern Siberia, a southwestward advanced and intensified subtropical high, and an elongated mid-latitude low in between. This mode mainly represents wet/dry trends over the 50-year period in the following regions: wetter summers in the Yangtze River valley and southwestern Japan, and drier summers in northern China and the Kinki area of Japan after the climate regime shift in the late 1970s. SVD2 and SVD3 are a pair of north-south wave patterns over the East Asia/western Pacific region with their phases in quadrature. The dominance of SVD2 or SVD3 implies a shift of the main rain band in China across the Yangtze River in the north-south direction, in association with very different rainfall patterns in Japan-either most of Japan experiences above- or below-normal rainfall in the same summer due to SVD2, or rainfall anomalies are opposite in sign between the Pacific side and the Sea of
\end{abstract}

Corresponding author: Hengyi Weng, LASG, Institute of Atmospheric Physics, Chinese Academy of Sciences, P.O. Box 9804, Beijing 100029, China.

E-mail: weng@lasg.iap.ac.cn

(C) 2004, Meteorological Society of Japan 
Japan side due to SVD3. These three dominant SVD spatial patterns, with their positive and negative phases, represent six dominant patterns of the western Pacific subtropical high and the mid-latitude wave systems in the regional large-scale circulation, in association with six main rain patterns in the two countries. The temporal behaviors of these modes will be further studied with wavelet and composite analyses in Part II.

\section{Introduction}

Eastern China and Japan are in the midlatitudes between the largest landmass of the world (the Eurasian continent) and the largest water mass (the Pacific Ocean), where the East Asian summer monsoon prevails due to the land/ocean thermal contrast in the region. Previous studies indicated that the summer rainfall in this region is greatly influenced by the East Asian summer monsoon and other factors, such as the subtropical high in the western Pacific, the mid-latitude low vortex and blocking high, land surface processes, the Pacific-Japan teleconnection pattern, the sea surface temperature (SST) anomalies in the vicinity oceanic areas as well as in the far eastern tropical Pacific, including El Niño-La Niña phenomena, etc. (e.g., Huang and Wu 1989; Nitta and $\mathrm{Hu}$ 1996; Zhao 1997; Kawamura 1998; Shen et al. 1998; Ninomiya 1999; Samel et al. 1999; Chang et al. 2000a,b; Huang et al. 2000; Lau et al. 2000; Kawamura et al. 2001; Krishnan and Sugi 2001; Chaolaw et al. 2001; Yang 2001). Because of the complexity of these variables and the interactions among them, the factors causing a similar above- or below-normal rainfall condition in the same area may be different in different summers. Spatial rainfall variability is even more important to Japan because of its narrow geographic shape. Two similar large-scale circulation patterns, with a small displacement in space, may cause two very different rainfall distributions in Japan.

The National Climate Center, China Meteorological Administration, has classified the summer rainfall anomaly percentile in eastern China (to the east of $105^{\circ} \mathrm{N}$ ) since 1951 into three types, based on the location of the dominant rain band in different latitudes (Zhao 1997; Zhao 2001). In Type I, the main rain band is located in the Yellow River valley and to its north, while the Yangtze River valley (YRV) is drier than normal. Meanwhile, there may be a secondary rain band in southern China. In Type II, the main rain band is be- tween the Yellow River and the Yangtze River, i.e., in the Huaihe River valley. The areas to the north of the Yellow River, and that to the south of the Yangtze River, are drier than normal. In Type III, the main rain band is in the YRV and the area to its south. Most area to the north of the Huaihe River is drier than normal. These rainfall types in China are influenced by at least ten factors (Zhao 1997), including the regional atmospheric circulation. Some of the rainfall variability in Japan may be related to the same factors that affect China's rainfall variability.

The summer rainfall variability in China and Japan may be a manifestation not only of regional climate change, but also of global climate change on different timescales. Many regional and global climate variables exhibited a sudden shift in climate regime in the late 1970s (e.g., Nitta and Yamada 1989; Trenberth and Hurrell 1994; Mitchell and Wallace 1996; Mantua et al. 1997; Suga et al. 2000). Some research identified such a shift as a phase change on interdecadal timescales of 15-20 years (Chao et al. 2000) or on the timescales longer than 35 years (Luo and Yamagata 2001). Some others considered the shift not simply as a phase change on a single timescale, but as a result of the superposition of the climate variability on several decadal-interdecadal timescales with the same ascending or descending phases (Lau and Weng 1999; Meehl et al. 2001). This shift in climate regime seems to be a long-term background for the Asian monsoon rainfall variability on shorter timescales. Extremely wet or dry summers in both China and Japan have occurred in different preferred areas before and after the late 1970s (Nitta and $\mathrm{Hu}$ 1996; Weng et al. 1999). It is expected that different dominant spatial rainfall patterns in both countries before and after this climate regime shift may be resulted from the climate variability with one or more longer timescales, which will be discussed in detail in Part II.

Although there are many factors that may influence the summer rainfall variability in 
East Asia, it is expected that many of the factors that influence the rainfall in East Asia be closely related through the regional atmospheric circulation. For example, the western Pacific subtropical high and monsoon are two important components of the regional atmospheric circulation. The regional and remote SST variability cannot influence the rainfall variability directly, and have to go through the atmospheric circulation, such as the western Pacific subtropical high and monsoon, to influence the rainfall variability in this region indirectly. When dealing with the rainfall variability that is influenced by complex and interacted multiple factors, we may proceed with individual factors separately to better understand the role of each factor, before proceeding with many factors concurrently. Even for a single factor, such as the regional circulation, the relationship between it and the rainfall is also complicated, because such a relationship is space- and time-dependant. In this work, we will only focus on the links between the extremely wet/dry conditions in China/Japan and the regional circulation on the interannualinterdecadal timescales for the summers of 1951-2000. Although the season-averaged data cannot give the relationship between the regional circulation and the rainfall variability on synoptic-scale, the information provided by the present analysis could be used to understand the climate background of the East Asian summer rainfall variability, with synoptic processes that are modulated on interannual-interdecadal timescales.

This work consists of two parts. Part I presents the first three SVD (singular value decomposition) modes by their spatial and temporal patterns of the covarying rainfall in the two countries and the large-scale regional circulation. Part II identifies the dominant timescales, on which the rainfall distribution with the three dominant spatial patterns would vary with time, and discusses the influence of the scale interaction and reinforcement among different timescales on the extremely wet and dry summers, in some preferred areas in China and Japan. Hopefully, the results found in this work will be helpful to the meteorologists in both countries. They may link the summer rainfall variability in their own country to that in the other one, through the regional large- scale circulation, and make a better statistical outlook of the summer rainfall in Japan (China), when the information on the summer rainfall outlook in China (Japan) is available.

In this part, Section 2 briefly describes the data sources and the methods we use. Section 3 documents the spatial and temporal patterns of the three dominant SVD modes. Section 4 shows the significance of these SVD modes by testing the temporal correlation coefficients between the observed and reconstructed rainfall anomalies, based on the SVD modes over the 50 years. Section 5 discusses what we have learned and may speculate from this analysis. Section 6 briefly summarizes the main results.

\section{Data and methods}

The analysis is limited to the summers (June, July and August) for the period of 19512000. The 160-station rainfall data for China are provided by Peking University, China, while the rainfall data for Japan are selected from the Annual Report of the Japan Meteorological Agency. We choose 72 stations in Japan such that the station distribution is as uniform as possible. Figure 1 shows the locations of the stations in both countries. The monthly $500 \mathrm{hPa}$ geopotential height and the $850 \mathrm{hPa}$ horizontal wind data are from the NCEP/ NCAR reanalysis (Kalnay et al. 1996). All seasonal anomalies are computed as the departures from the summer means over the period of 1951-2000. The summer rainfall is the total for the three months, while other variables are seasonally averaged.

The SVD analysis (Bretherton et al. 1992; Wallace et al. 1992) is used to find the dominant modes of the co-variability between the combined China/Japan rainfall anomaly and the $500 \mathrm{hPa}$ geopotential height anomaly in the area of $60^{\circ} \mathrm{E}-160^{\circ} \mathrm{W}, 20^{\circ} \mathrm{S}-70^{\circ} \mathrm{N}$. We use the linear regression of the $850 \mathrm{hPa}$ horizontal wind anomaly field against the temporal coefficients (or principal components) of the rainfall of the dominant SVD modes, to find the dominant co-varying, low-level atmospheric circulation patterns.

\section{SVD modes}

Figure 2 gives the mean spatial patterns of the $500 \mathrm{hPa}$ geopotential height, the $850 \mathrm{hPa}$ horizontal wind, as well as the rain- 

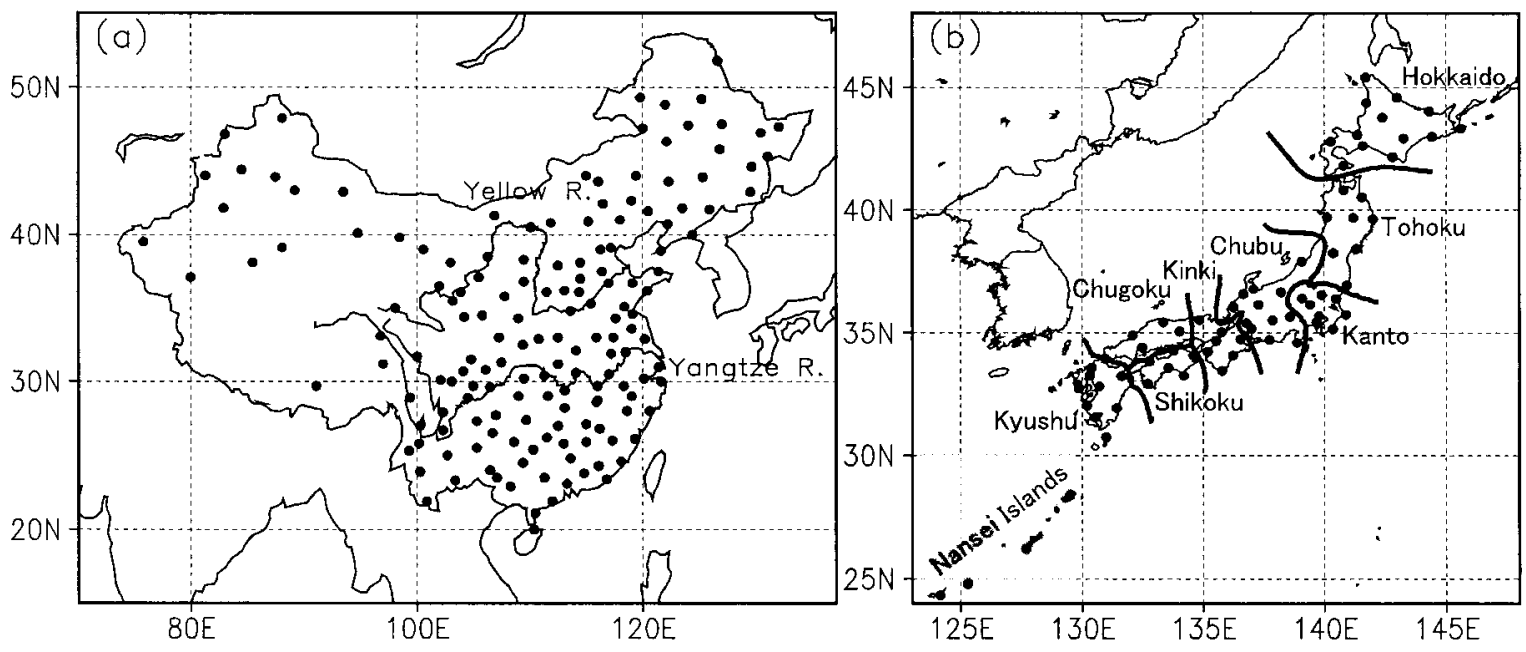

Fig. 1. Station distribution where the rainfall data were collected in (a) China (160 stations) and (b) Japan (72 stations). The spatial scale in (b) has been enlarged for a better resolution in Japan. Some areas and rivers are labeled for the convenience of description.

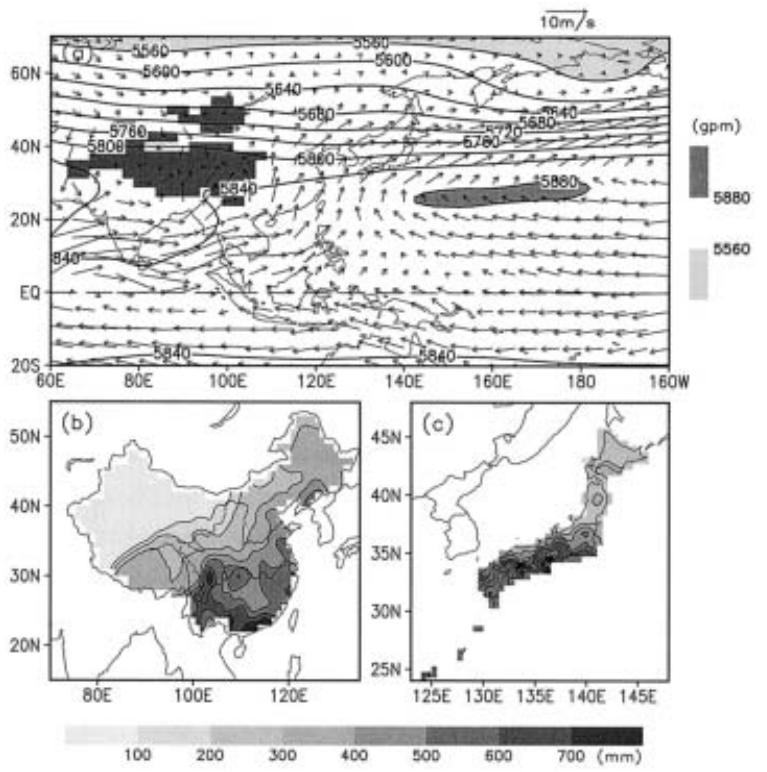

Fig. 2. The mean fields averaged over the summers of 1951-2000 for (a) the $500 \mathrm{hPa}$ geopotential height and the $850 \mathrm{hPa}$ horizontal wind, (b) the rainfall in China, and (c) the rainfall in Japan. The contour interval for the geopotential height is $40 \mathrm{gpm}$, and for the rainfall is $100 \mathrm{~mm}$. The grids with topography higher than $1500 \mathrm{~m}$ is marked by dark shading, so that the $850 \mathrm{hPa}$ wind in these areas are only for reference. fall in China and Japan, averaged over the summers of 1951-2000. Figure 2a shows the mean position of the western Pacific subtropical high around $160^{\circ} \mathrm{E} 25^{\circ} \mathrm{N}$ at $500 \mathrm{hPa}$. In eastern China and Japan, the mean horizontal wind at $850 \mathrm{hPa}$ is basically the southwest monsoon, which is mainly the cyclonic flows related to the Indian low in the west, and the anticyclonic flows related to the western Pacific subtropical high in the east. The mean rainfall in China (Fig. 2b) is basically decreased from southeast to northwest, with the mid-reach of the Yangtze River having relatively larger rainfall than its immediate southern area. In Japan (Fig. 2c), the mean rainfall is basically decreased from the mid-Japan $\left(33^{\circ} \mathrm{N}-36^{\circ} \mathrm{N}\right)$, which includes most of Kinki and southern Chubu, to both south and north, except for the far southwestern area of the Nansei Islands. In the following discussion, we analyze the anomalies that are departures from these mean fields, and present the SVD components of these anomaly fields. In general, the term of anomaly will be omitted, if not specified otherwise.

For each SVD mode, we will show the spatial patterns of the $500 \mathrm{hPa}$ geopotential height, the $850 \mathrm{hPa}$ horizontal wind, and the rainfall in China and Japan, as well as the temporal coefficients of the geopotential height and the rainfall; the latter is for the rainfall in both 
countries. In the SVD spatial pattern of a given variable (the $500 \mathrm{hPa}$ geopotential height or rainfall), the value at a given location shows the $1-\sigma$ (standard deviation) of that variable in that location. The temporal coefficient (dimensionless) for a summer shows how many standard deviations of the $500 \mathrm{hPa}$ geopotential height, or rainfall distribution, contributed by this SVD mode to the total rainfall anomaly that is linked to the regional $500 \mathrm{hPa}$ geopotential height in that summer. In the following, the description for a spatial pattern is for a summer when its temporal coefficient is positive, if not specified otherwise. Based on the criterion of North et al. (1982), the sampling error between SVD1 and SVD2, as well as that between SVD3 and SVD4, are well separated from each other, while that between SVD2 and SVD3 is not. Thus SVD2 and SVD3 may be considered as a pair to represent some kind of oscillation of the covariability, which will be shown later in this section. Here we only discuss the three dominant modes, i.e., SVD1, SVD2, and SVD3.

\section{$3.1 \quad S V D 1$}

SVD1 (Fig. 3) explains $43.3 \%$ of the total squared covariance between the combined rainfall in the two countries and the regional $500 \mathrm{hPa}$ geopotential height for the 50 summers. At $500 \mathrm{hPa}$ (Fig. 3a), there is a "positive-negative-positive" wave pattern from north to south over the East Asia/western Pacific region. Except for a zonally elongated negative center near $40^{\circ} \mathrm{N}$ between $120^{\circ} \mathrm{E}$ and $175^{\circ} \mathrm{E}$, most areas in the region exhibit positive signs. This situation probably corresponds to a blocking high in eastern Siberia, a cut-off low over the Sea of Japan, and a subtropical high in southeastern Asia/western Pacific, which zonal axis is slightly located to the north of $20^{\circ} \mathrm{N}$. This situation also implies that the western Pacific subtropical high has advanced southwestward, from its mean position shown in Fig. $2 a$. At $850 \mathrm{hPa}$, the larger northerly wind in eastern China implies that the Asian monsoon is weaker than normal in most areas over East Asia, except for the coastal area in southeastern China and southern Japan, where are the northern edge of the subtropical high. The weakened monsoon in the north, with an intensified monsoon in the south, results in a con-
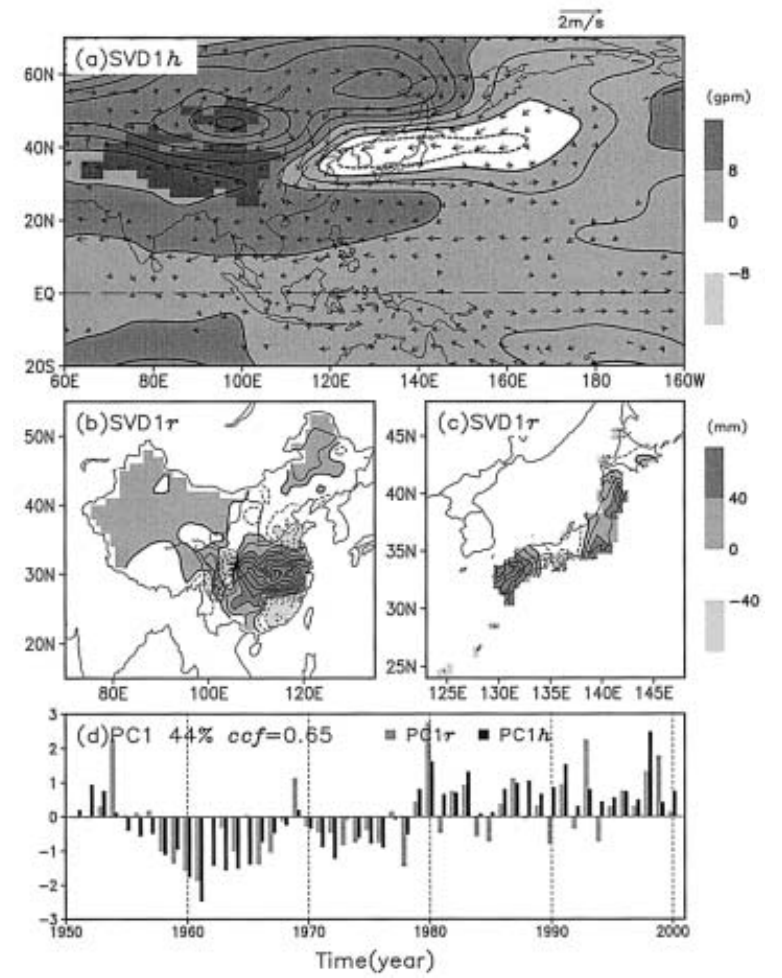

Fig. 3. The spatial and temporal patterns of SVD1. (a) The spatial $500 \mathrm{hPa}$ geopotential height pattern and the $850 \mathrm{hPa}$ horizontal wind pattern, the latter is the observed wind field linearly regressed against $\mathrm{PC} 1 r$. The grids with topography higher than $1500 \mathrm{~m}$ are marked by dark shading. (b) and (c) are the spatial rainfall patterns in China and Japan, respectively. The contour interval in (a) is $4 \mathrm{gpm}$, while that in (b) and (c) is $20 \mathrm{~mm}$. The magnitude at a grid in the spatial patterns is the one standard deviation of the variability that this mode at this grid contributing to the total squared covariance. (d) The temporal coefficients of the mode for the $500 \mathrm{hPa}$ geopotential height (PC1h) and those for the combined rainfall in China and Japan (PC1r). The units in (d) are the "standard deviation" of the corresponding variables.

vergence zone along the southwestern edge of the elongated mid-latitude low, extending from the mid- and low-reaches of the Yangtze River to southwestern Japan, which favors the formation of a rain band over there. 
The rainfall in China (Fig. 3b) exhibits a typical wet YRV, similar to a Type III rainfall pattern in China. The main rain bands over the YRV and southwestern Japan (Fig. 3c) are both related to the convergence zone that is between the subtropical high and the midlatitude low. There is also a secondary rain band in northeastern China and a similar one in the Pacific side of Japan from Tohoku to Kanto. These northern rain bands correspond to the northeast wind between the blocking high and the low vortex in Fig. 3a, which may bring moist air from northwestern Pacific to northeastern China and the Pacific side of Japan in Tohoku and Kanto (Fig. 3c). The continental high and the western Pacific subtropical high on the north and south sides, respectively, of the convergence zone are responsible for the dry areas in northern and southern China, Kinki and the Nansei Islands of Japan.

In the time domain (Fig. 3d), starting in the mid-1950s, the pre-1977 period (Period I) is dominated by negative coefficients $(\mathrm{PC} 1 h<0$, $\mathrm{PC} 1 r<0$ ), while the post-1977 period (Period II) is dominated by positive coefficients ( $\mathrm{PC} 1 h$ $>0, \mathrm{PC} 1 r>0$ ), which is consistent with many earlier studies about the global and regional climate shift in the late 1970s. In addition, there are also some interannual and decadalinterdecadal variability. This mode has a large contribution to the wet summers in the YRV and southwestern Japan, and sometime also the above-normal rainfall in Tohoku and Kanto, in Period II, e.g., the summers of 1980, 1993, 1998 and 1999. The dominant timescales, and their combined effect of the SVD modes on major wet and dry summers during the 50 years, will be discussed in Part II.

When $\mathrm{PC} 1 h<0$, there is a "negative-positivenegative" wave pattern in the $500 \mathrm{hPa}$ geopotential height pattern from north to south over the East Asia/western Pacific region. There is a negative center in eastern Siberia in addition to the main negative center over Mongolia, and an elongated positive center over the Sea of Japan, reflecting a northward and westward advance of the western Pacific subtropical high to around $40^{\circ} \mathrm{N}$, which causes the summers drier than normal in southwestern Japan (Fig. 3c), and in the YRV of China (Fig. 3b). The vast area to the south of $30^{\circ} \mathrm{N}$ in the East Asia/ western Pacific region is negative. At $850 \mathrm{hPa}$, the southwest monsoon in East Asia is stronger than normal, which "pushes" the convergence zone, associated with the main rain band, northward from its normal position, and causes above-normal rainfall occurred in the Yellow River valley. This circulation pattern favors the Type I rainfall pattern in China. In Japan, while the southwestern area is drier, the Kinki area is wetter than normal. Such a wet/dry distribution occurred more often before the later 1970s, e.g., the SVD1 mode has a large negative contribution to the similar rainfall patterns for four consecutive summers from 1958 to 1961 .

\section{$3.2 \quad$ SVD2}

SVD2 (Fig. 4) explains about $15 \%$ of the total squared covariance. At $500 \mathrm{hPa}$ (Fig. 4a), from the high- to low-latitudes over the East Asia/ western Pacific region, there is a "negativepositive-negative" wave pattern, which is slightly located to the east of the wave pattern in SVD1h (Fig. 3a). An enhanced polar vortex extends its center to $140^{\circ} \mathrm{E} 57^{\circ} \mathrm{N}$. A positive

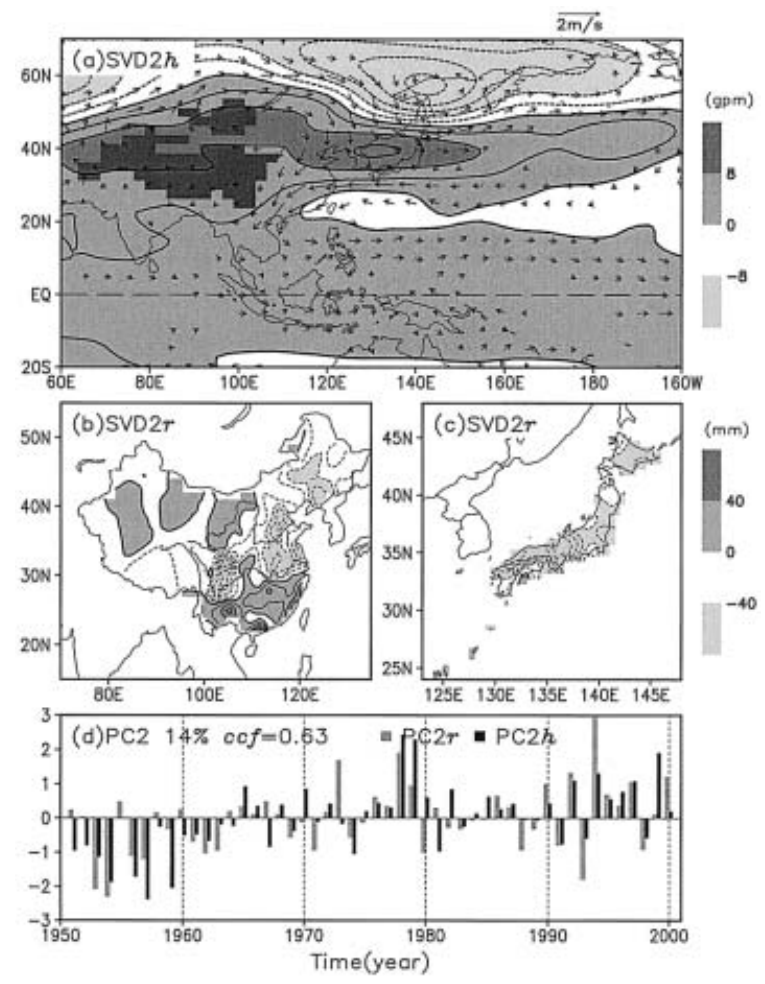

Fig. 4. Same as in Fig. 3, except for SVD2. 
band is around $40^{\circ} \mathrm{N}$ across the region, which contains the positive center over the Sea of Japan, and the ridge to its west between $90^{\circ}-$ $110^{\circ} \mathrm{E}$. Thus, most of northern China and most areas of Japan are under the influence of the positive band of the $500 \mathrm{hPa}$ geopotential height. Around $23^{\circ} \mathrm{N}$, a weak and zonally oriented negative band extends from China's southeastern coastal area and Taiwan to the central Pacific. At $850 \mathrm{hPa}$, most of China except for the southern area, and almost the entire Japan are under the influence of the anticyclonic wind. The southwest monsoon is weaker than that in SVD1 (Fig. 3a), and the convergence zone is retreated back to the south, along the southeastern coast of China.

For the rainfall in China (Fig. 4b), the distribution is divided by the Yangtze River. This mode reflects the below-normal rainfall in northern China, while above-normal rainfall to the south of the Yangtze River, i.e., the rain bad in SVD2 is to the south of that in SVD1. This mode contributes to a Type III rainfall pattern in China. In Japan (Fig. 4c), except for the far southwestern area of the Nansei Islands, the rainfall in most areas of the country is below normal.

In the time domain (Fig. 4d), although a regime shift in the late 1970 s or a trend signal also exists, it is much weaker than that in SVD1 (Fig. 3d). Therefore, at a given place where the spatial coefficients in both SVD1 and SVD2 are large, the actual trend should be the combination of the two modes. The $2-3 \mathrm{yr}$ variability is apparent, especially in the $1990 \mathrm{~s}$, which will be discussed in detail in Part II.

When $\mathrm{PC} 2 h<0$, the East Asia/western Pacific region exhibits a "positive-negativepositive" north-south wave pattern. It could be a blocking situation over the coastal area of eastern Siberia, when PC2 $h$ is negatively large. Such a blocking high seems to be located to the east of the blocking center in SVD1 when $\mathrm{PC} 1 h>0$. The western Pacific subtropical high has advanced southwestward from its normal position to around $23^{\circ} \mathrm{N}$, but to the northeast of its position in SVD1 (Fig. 3a). There is a low band of the $500 \mathrm{hPa}$ geopotential height in the mid-latitudes, which may be a storm track running from the Eurasia continent to the western Pacific and beyond the Dateline. The southwest monsoon is enhanced and advanced northward.
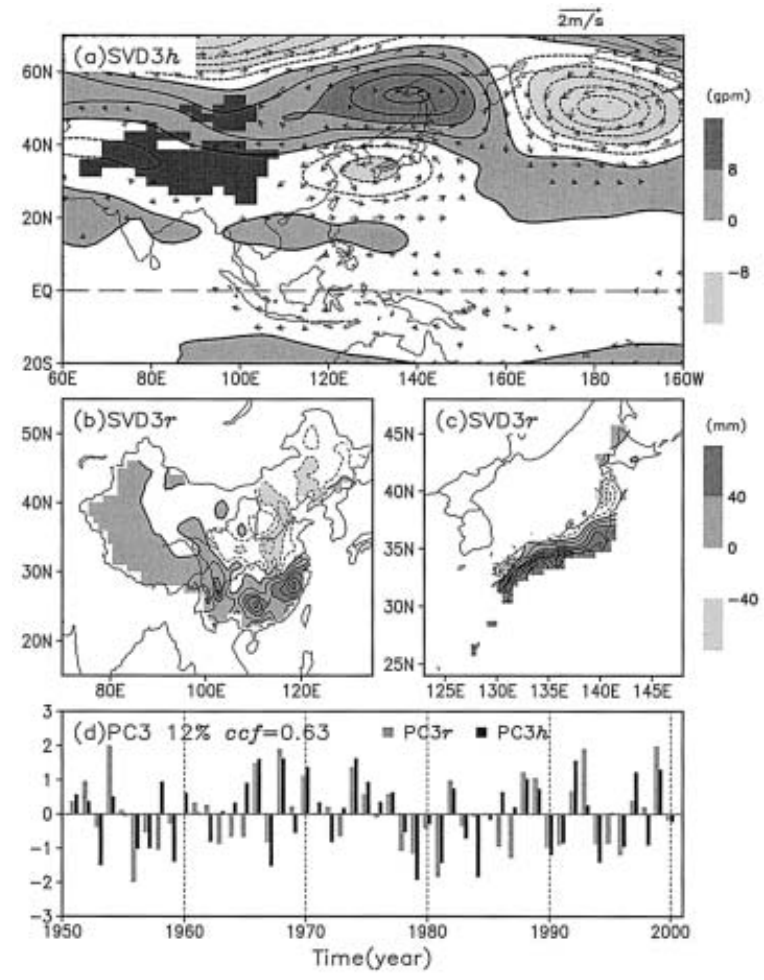

Fig. 5. Same as in Fig. 3, except for SVD3.

It is a large-scale climate background for synoptic systems to be active in the mid-latitudes, bringing above normal rainfall over its path, i.e., in the area to the north of the Yangtze River and most areas of Japan, especially in the western Chugoku, Shikoku and Kinki areas. This negative SVD2 mainly contributes to a Type II rainfall pattern in China, as well as to some Type I pattern.

\section{$3.3 \quad$ SVD3}

SVD3 (Fig. 5) explains 12\% of the total squared covariance. At $500 \mathrm{hPa}$ (Fig. 5a), there is also a "positive-negative-positive" northsouth wave pattern in the East Asia/western Pacific region, in a similar longitude area with that of SVD2h (Fig. 4a), but with a southward shift by about 7-8 degrees in latitude, or a quarter of phase shift, from the north-south wave pattern in SVD2 $h$ when $\mathrm{PC} 2 h<0$. A strong positive center is over the coastal area of eastern Siberia around $138^{\circ} \mathrm{E} 50^{\circ} \mathrm{N}$, enhancing the ridge over the Okhotsk Sea, where it could have a blocking high in a summer with a large 
PC3h. A negative center is over southwestern Japan around $32^{\circ} \mathrm{N} 130^{\circ} \mathrm{E}$. To its south, a weak positive anomaly area extends from the SubContinent, crossing the Philippines, to the subtropical western Pacific. This situation implies that the western Pacific subtropical high might have advanced southwestward to around $18^{\circ} \mathrm{N}$, which is the most southern location that the subtropical high may be represented by any one of the three dominant SVD modes. Longitudinally, from the subtropics to the mid-latitudes, there are centers to the east of $150^{\circ} \mathrm{E}$, which are out-of-phase with those to the west of $150^{\circ} \mathrm{E}$. This situation is rather different from that in SVD2 $h$, where the $500 \mathrm{hPa}$ geopotential height has little longitudinal variation over this region. At $850 \mathrm{hPa}$, the northeast wind is in generally weaker than that in SVD2 over eastern China, except for the southeastern coastal area, where the weak southwest wind prevails. This situation implies a convergence zone over southern China, which extends northeastward, crossing the negative center of the $500 \mathrm{hPa}$ geopotential height. The enhanced southwest monsoon, between the northern frank of the western Pacific subtropical high and the southern frank of the mid-latitude low, may bring moisture into southern China and the Pacific side of Kyushu, Shikoku, and southeastern Honshu of Japan.

In China (Fig. 5b), most area to the north of the Yangtze River has below-normal rainfall, while the area to the south has above-normal rainfall, contributing to a Type III rainfall pattern in China. This pattern looks similar to that in SVD2. However, based on the magnitude of the spatial coefficients of the two modes, SVD2 (Fig. 4b) emphasizes larger rainfall variability in the area to the north of the Yangtze River than that to the south, while SVD3 (Fig. $5 b)$ emphasizes larger rainfall variability in the area to the south of the Yangtze River than that to the north.

In Japan (Fig. 5c), this mode basically contributes a rain band running from southwest to northeast. Japan, to the south of Tohoku, is divided into narrow areas with opposite signs between the Pacific side, having above-normal rainfall, and the Sea of Japan side, having below-normal rainfall. Most areas of Tohoku is basically drier than normal, especially in its Sea of Japan side. This is different from SVD2, where most areas of Japan may concurrently have above- or below-normal rainfall. The above-normal rainfall in most areas of the Pacific side of Japan, as well as the Nansei Islands, is related to the rainfall in southern China, where the moisture is brought in by the southwest monsoon.

In the time domain (Fig. 5d), there are only interannual and decadal-interdecadal timescales, without discernable trends in the temporal coefficients, for both PC3h and PC3r. When PC3h $<0$, the East Asia/western Pacific region exhibits a "negative-positive-negative" northsouth wave pattern. It is not a blocking situation. The western Pacific subtropical high has advanced northwestward to around $32^{\circ} \mathrm{N} 130^{\circ} \mathrm{E}$, i.e., over the southern Sea of Japan. The $850 \mathrm{hPa}$ horizontal winds in the northwestern part of the subtropical high enhance the southwest monsoon. Correspondingly, the main rain bands in both countries are moved northward. The above-normal rainfall in China is to the north of the Yangtze River, and that in Japan is to the Sea of Japan, especially in northwestern Kyushu and western Tohoku. The negative SVD3 contributes to Type I and Type II rainfall patterns in China.

Figures $4 \mathrm{a}$ and $5 \mathrm{a}$ show the north-south wave shift with about a quarter of phase difference between SVD2 and SVD3 in the longitudes $120^{\circ} \mathrm{E}-150^{\circ} \mathrm{E}$. The difference in rainfall patterns between Figs. $4 \mathrm{c}$ and $5 \mathrm{c}$ shows that the rainfall in Japan is very sensitive to a small latitudinal displacement of similar regional circulation systems, due to the dominance between SVD2 and SVD3, which may bring in or block the moisture for different areas of Japan, resulting in different rainfall distributions.

Before we further discuss the temporal behavior of the co-varying regional circulation, and the rainfall in China and Japan in Part II, we need to know whether these dominant SVD modes are able to statistically represent the observed rainfall anomalies in China and Japan, at a certain confidence level. This will be the focus of the next section.

\section{Significance of the SVD modes}

To find the credibility of the SVD modes contributing to the observed rainfall anomaly distribution, we calculate the temporal correlation between the observed rainfall anomalies 

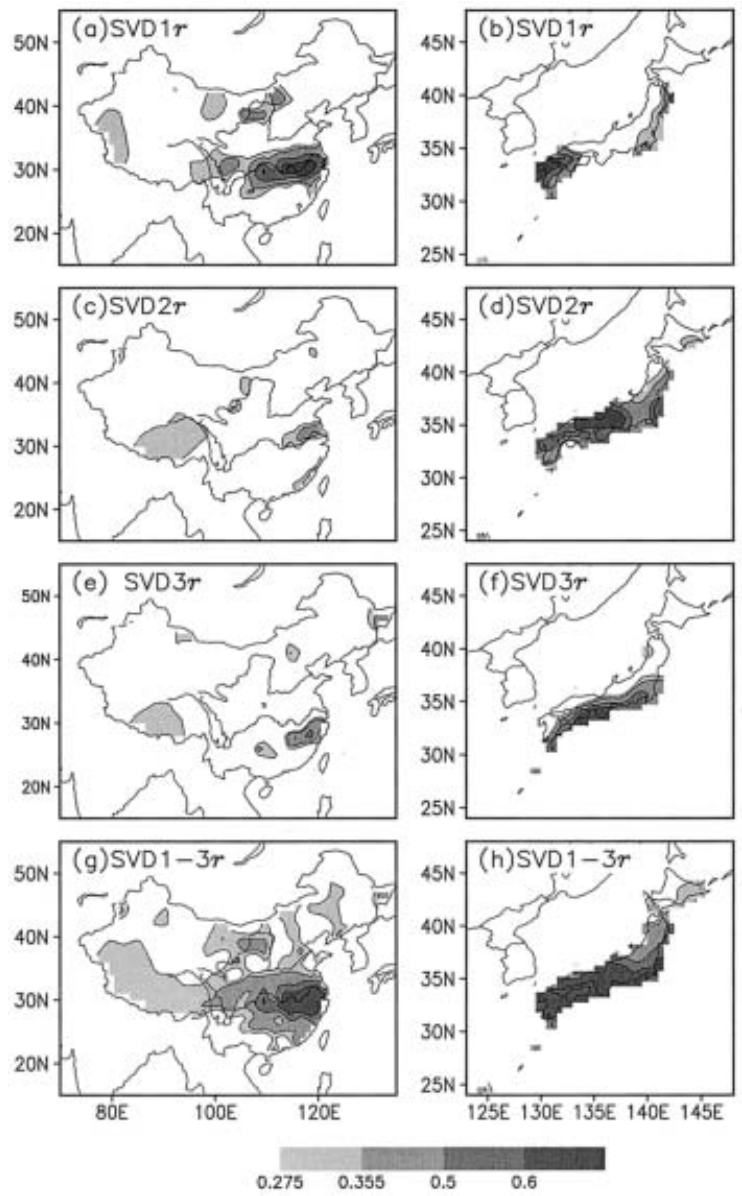

Fig. 6. Temporal correlation coefficients between the observed and the reconstructed rainfall anomaly patterns. From the top to the bottom, the panels show the correlation coefficients using the reconstructed rainfall patterns based on individual SVD1, SVD2, and SVD3, as well as the combined pattern SVD1-3, respectively, for China (left panels) and Japan (right panels). The correlation coefficients that are significant at the $95 \%$ and $99 \%$ confidence levels for the 50 years are 0.275 and 0.355 , respectively.

in China/Japan and the reconstructed rainfall anomalies, based on each of the first three modes as well as their combination, and present the results in Fig. 6. The correlation coefficients will be examined by the Student's $t$ test at different confidence levels. The number of the summers, 50, is considered as the de- grees of freedom for the Student's $t$-test. The criteria for a correlation coefficient to pass the test at the $95 \%$ and $99 \%$ of confidence levels are 0.275 and 0.355 , respectively.

Figures $6 \mathrm{a}$ and $6 \mathrm{~b}$ show the correlation coefficients between the observed rainfall and the reconstructed rainfall based on only SVD1 for China and Japan, respectively. The eastern China between $27^{\circ} \mathrm{N}-33^{\circ} \mathrm{N}$ basically passes the significance test at the $95 \%$ confidence level. In the lower reach of the Yangtze River, the correlation coefficients are over 0.5 , which is significant above the $99.99 \%$ confidence level. There is a secondary significant area (at least at the 95\% level) in southwestern Inner Mongolia and the mid-reach of the Yellow River. In Japan, the correlation coefficients in the southwestern part of the main islands, as well as the Pacific side of Tohoku, are significant at least at the $95 \%$ confidence level. The correlation coefficients in Kyushu, and the western parts of Chugoku and Shikoku, are significant above the 99.99\% confidence level. Comparing Figs. 6a and $6 \mathrm{~b}$ with Figs. $3 \mathrm{~b}$ and $3 \mathrm{c}$, we find that the areas with 95\% confidence level are mainly those with a regime shift in the late 1970s from a below-normal to an above-normal rainfall. There are some areas that have insignificant correlation even when the values shown in Figs. $3 \mathrm{~b}$ and $3 \mathrm{c}$ are not very small, e.g., the negative area in Kinki and Shikoku of Japan. In these areas, the observed rainfall in Period II has been reduced from Period I. Care must be taken when interpreting the rainfall anomaly in these areas by SVD1 alone.

For SVD2, in China (Fig. 6c), the area with significant correlation coefficients, at the $95 \%$ confidence level, is basically limited to a zonal band to the neighboring north of the Yangtze River. Some of the correlation coefficients are significant above the 99\% confidence level. Along the southeast coast, there is also a very narrow area where the correlation coefficients are significant above the $95 \%$ confidence level. However, in Japan (Fig. 6d), except for most areas of Hokkaido and northwestern Tohoku, the correlation coefficients in the country to the south of $38^{\circ} \mathrm{N}$, are basically significant at least at the 95\% confidence level. In Kinki, Shikoku and southeastern Tohoku, the correlation coefficients are significant, even above the $99.99 \%$ confidence level. When a temporal coefficient is 
negatively large, SVD2 has an important contribution to China's Type II or Type I rainfall pattern. Thus, when the area to the north of the Yangtze River experiences above-normal rainfall, most areas of Japan may also experience above-normal rainfall. The opposite may happen, i.e., when the area to the north of the Yangtze River experiences below-normal rainfall, many areas in Japan may also experience below-normal rainfall, especially the Kinki area where an extremely dry summer may occur, which occurred more often in Period II than in Period I.

For SVD3, in China (Fig. 6e), the area with significant correlation coefficients at the $95 \%$ confidence level, is basically limited to a zonal band to the neighboring south of the Yangtze River. In Japan (Fig. 6f), such an area is basically limited to the Pacific side of Japan to the south of $37^{\circ} \mathrm{N}$. The significant area for SVD3 implies that when the main rain band in China is limited to the neighboring south of the Yangtze River, the area with above-normal rainfall in Japan may be in the Pacific side to the south of Tohoku. The patterns of Figs. 6c-f show the rain band shift between SVD2 and SVD3, in the north-south direction in both countries.

When the first three SVD modes are combined to reconstruct the rainfall anomaly, in China (Fig. 6g), the correlation coefficients in most areas of eastern China are significant above the $95 \%$ confidence level. The area in the YRV due to SVD1 (Fig. 6a), and the neighboring areas to its north due to SVD2 (Fig. 6c), and to its south due to SVD3 (Fig. 6e), have connected to one another where the correlation coefficients are significant at the $99 \%$ confidence level. In Japan (Fig. 6h), the reconstructed pattern is even better, because the correlation coefficients in most area to the south of $40^{\circ} \mathrm{N}$ are significant at the $99 \%$ confidence level, with the highest correlation in southwestern Japan. Note that the significant areas in the combined modes for the two countries (Figs. 6g and 6h), are larger than the sums of the significant areas based on the individual modes. It is because some seemingly insignificant contributions from the individual modes, may add up to make the combined reconstructed patterns be more statistically significant when these insignificant contributions from the individual modes have the same-sign contribution, and large enough to make "useful" contribution to the observed rainfall patterns.

\section{Discussions}

The results from previous sections show that using the first three SVD modes to find extremely wet and dry summer rainfall patterns in China and Japan that are linked to the East Asia/western Pacific regional large-scale circulation for the 50 years is rather reliable. The significance of the correlation coefficients between the observed and the reconstructed rainfall anomalies for different areas are at different confidence levels. The causes for the insignificant correlations in some areas are complicated. First, SVD modes analyzed here represent only part of the rainfall variability in China and Japan that is linked to the large-scale regional $500 \mathrm{hPa}$ geopotential height variability, but not the part of the rainfall variability caused by other factors that are not related to the large-scale regional circulation. Second, some rainfall patterns may be represented by higher-order SVD modes that we have not included in the reconstruction.

The dominance of either SVD2 or SVD3 would be especially important to Japan, because of its narrow geographic shape. A shift in the dominance between SVD2 and SVD3 shows a shift in rain band in China from the north of the Yangtze River (SVD2) to the south (SVD3), with a few degrees in latitude. However, a shift in rainfall band with a few degrees in latitude in Japan may result in a completely different rainfall pattern: most areas of Japan may be drier (positive SVD2, e.g., 1994) or wetter (negative SVD2, e.g., 1953) concurrently, or the Pacific side and the Nansei Islands are wetter while the Sea of Japan side is drier (positive SVD3, e.g., 1968) or the opposite may occur (negative SVD3, e.g., 1981). The extreme cases with the contribution from only one mode may rarely occur. In fact, a rainfall distribution in a summer often appears as a combination of a few dominant modes. The relative contribution from each mode will determine the specific wet/ dry areas for a summer. For example, in the summers of 1992 and 1994, the contribution from SVD2 are both positive, but the contribution from SVD3 is positive in the summer of 1992 while negative in the summer of 1994. 
The combined contribution from SVD2 and SVD3 is such that the positive center of the $500 \mathrm{hPa}$ geopotential height is positioned to the north (south) of the center shown in SVD2 (Fig. 4a) in the summer of 1992 (1994). As a result, although most areas of Japan were drier than normal, the detailed rainfall distribution and the severity of dryness were different between the two summers, which may be due to the opposite contributions from SVD3. In the summer of 1992, most areas of Japan were drier than normal, due to a large contribution from a positive SVD2, except for the Pacific side of Kyushu and Shikoku as well as the Nansei Islands, where were wetter than normal due to a positive SVD3 contribution, which was partially cancelled by the dry contribution from the positive SVD2. If the contribution from SVD3 were negative, the above-mentioned area in the summer of 1992 would be much drier than normal. This was what happened in the summer of 1994, when most areas in Japan were drier than normal, reflecting a predominant positive contribution from SVD2. The contribution from the negative SVD3 in the summer of $1994 \mathrm{ex}-$ acerbates the dry condition in the Pacific side of Kyushu and Shikoku, as well as the northern Nansei Islands.

The fact that the significant temporal correlation coefficients appear in the YRV and it's neighboring northern and southern areas in China, and in most areas of Japan, except for western Hokkaido, may be a manifestation that the rainfall variability in these areas are largely influenced by the large-scale regional circulation, which contains two main factors that influence the summer rainfall variability in these areas, i.e., the southwest monsoon and the western Pacific subtropical high. Weng et al. (1999) studied the link between China's rainfall and the global SST anomaly. They found that the rainfall in northern China has the highest negative correlation with the SST in the eastern tropical Pacific (Equator, $80^{\circ}-$ $110^{\circ} \mathrm{E}$ ), which is significant above the $99 \%$ confidence level, and that the rainfall in the YRV area has insignificant correlation with the SST in the same oceanic area. However, the rainfall in the YRV area has a significant positive correlation, at the $99 \%$ confidence level, with the SST in the western subtropical Pacific area, around $20^{\circ} \mathrm{N}$ between $130^{\circ} \mathrm{E}-150^{\circ} \mathrm{E}$. Their re- sults may reflect a strong influence of the SST in the neighboring western subtropical Pacific, through the large-scale regional circulation, on the rainfall anomaly in the YRV area (Wu and Liu 1995). The current results have further confirmed that the regional large-scale circulation, over the East Asia/western Pacific region, which has a close relationship with the SST in the western Pacific, has a large impact on the rainfall variability in the YRV area in China. Based on the SVD analysis, most areas of Japan, except for western Hokkaido, is therefore also largely influenced by the regional large-scale circulation.

All the three dominant SVD modes show north-south wave patterns in the East Asia/ western Pacific region, with some phase shift in both latitude and longitude. These wave patterns are closely related to the location and intensity of the subtropical high and the midlatitude wave activity, which jointly affect the location and intensity of the main rain bands in both countries. For example, a large positive (negative) SVD1 plays a predominant role in Type III (I) rainfall pattern in China. Negative SVD2 and positive SVD3 are crucial to Type II and Type III rain band in China, depending on their sign and relative contribution from the two modes. Although SVD2 and SVD3 explain much less fractions of the total squared covariance than SVD1 does, the couple plays an important role in adjusting the wet/dry areas in both countries in addition to SVD1, especially in Japan. There are positive or negative centers of the $500 \mathrm{hPa}$ geopotential height over the Sea of Japan in all the three SVD modes, with some shift in space. The resultant patterns of the $500 \mathrm{hPa}$ geopotential height with different dominance of the SVD modes reflect different disposition of the surrounding systems, such as the western Pacific subtropical high, the blocking high over Siberia, and the mid-latitude storm track, etc. The resultant situations of these systems, due to different dominance of a mode or a few modes, may largely determine the rainfall distributions in China and Japan.

In practice, a key question to ask is whether we can eventually predict which SVD mode(s) will become dominant for the coming summer(s). To answer this question requires an understanding of how, and on what dominant 
timescales, these modes are varying, which will be explored in Part II.

The significant areas in the three SVD modes are mainly those that exhibit larger rainfall variability. The result shown in Fig. 6 is only based on a "statistical test" for the linearly decomposed SVD modes of the rainfall and the regional circulation. The modes may actually have complicated nonstationary and nonlinear behaviors that would hardly be represented by a few dominant SVD modes. Thus, whether a significant test can pass or not at certain confidence level, should not be considered as a sole criterion to decide whether an assumption about a relationship, between the rainfall and circulation, should be accepted or rejected. A rainfall-circulation relationship that is less significant statistically may appear physically, which also deserves a further exploration, because it may be an extreme event that occurs with a small statistical significance.

\section{Summary}

We use the SVD analysis to decompose the covariance of the combined summer rainfall in China/Japan with the $500 \mathrm{hPa}$ geopotential height in the East Asia/western Pacific region $\left(60^{\circ} \mathrm{E}-160^{\circ} \mathrm{W}, 20^{\circ} \mathrm{S}-70^{\circ} \mathrm{N}\right)$ for $1951-2000$ into dominant modes. An additional analysis of the $850 \mathrm{hPa}$ horizontal wind over the same region is performed by linear regression. The results shed some light on possible links between the regional large-scale circulation in the middle and lower troposphere and the summer rainfall variability in China and Japan in the 50 summers. The main spatial features of the three dominant SVD modes, in their positive phases, are:

- SVD1: At $500 \mathrm{hPa}$, an intensified and southwestward advanced western Pacific subtropical high is around $120^{\circ} \mathrm{E} 20^{\circ} \mathrm{N}$, a blocking high over eastern Siberia, and an elongated midlatitude low in between. The southwest monsoon is weaker in the north, while stronger in the south, resulting in a convergence zone from the YRV to southwestern Japan. This mode mainly reflects wet/dry trends in the two countries over the 50 years. Specifically, it reflects the wet trends in the YRV, northeastern China, northern Kyushu, Kanto and the Pacific side of Tohoku, while the dry trends in northern and southern China, the Kinki area and the Nansei Islands of Japan.

- SVD2: At $500 \mathrm{hPa}$, a north-south wave pattern of the geopotential height in the region between $120^{\circ} \mathrm{E}-150^{\circ} \mathrm{E}$ is slightly to the east of that in SVD1, with a positive center over the Sea of Japan. The southwest monsoon wind at $850 \mathrm{hPa}$ is weaker than that in SVD1. Accordingly, the contribution of this mode to the rainfall is negative in the area to the north of the Yangtze River, while positive to its south. The contribution to the rainfall in Japan is negative in most areas. The temporal behavior of SVD2 exhibits a weak trend, with large interannual variability.

- SVD3: At $500 \mathrm{hPa}$, it has a similar large-scale north-south wave pattern as SVD2's in the land-ocean board region, with a phase shift in quadrature. That is, a negative center of the geopotential height is over the southern Sea of Japan, while the subtropical high is located to the south of $20^{\circ} \mathrm{N}$. Correspondingly, a zonal convergence zone is running from southern China to the Pacific side of Japan, to the south of Tohoku. The most positive contribution to the rainfall in China is in the area to the south of the Yangtze River, while that in Japan is in the Pacific side to the south of Tohoku. SVD3 does not exhibit a trend.

In fact, the three dominant SVD spatial patterns, with positive and negative phases, represent six dominant patterns of the western Pacific subtropical high and the mid-latitude wave systems in the regional circulation, which would link to six main rainfall patterns in the two countries, if only one mode is predominant. However, in reality, the combined contribution from these modes, with different signs and weights, is often seen in most summers, resulting in a wide variety of rainfall distribution, influenced by the regional circulation from one summer to another.

The areas with wet/dry trend provide long-term background for extremely wet/dry summers to occur on interannual-interdecadal timescales, which will be discussed in Part II in detail.

\section{Acknowledgments}

The authors are very grateful to Prof. Wang Shaowu for providing China's rainfall data and 
inspirational discussions. Sincere thanks also go to Dr. Ryo Furue for his various helps and discussions during this research, and to Ms. Chikako Katsuki for her careful drawing in Figure 1. The authors are also thankful to the two anonymous reviewers of Part I for their constructed comments. HYW was mainly supported by the Center for Climate System Research, University of Tokyo through its Visiting Professor Program. During the later stage of this work, she was supported by the Director's Fund of LASG, and the Innovative Fund, of the Institute of Atmospheric Physics, Chinese Academy of Sciences.

\section{References}

Bretherton, C.S., C. Smith, and J.M. Wallace, 1992: An intercomparison of methods for finding coupled patterns in climate data. J. Climate, $\mathbf{5}$, $541-560$.

Chang, C.P., Y.S. Zhang, and T. Li, 2000a: Interannual and interdecadal variations of the East Asian summer monsoon and tropical Pacific SSTs. Part I: Role of the subtropical ridge. J. Climate, 13, 4310-4325.

, , and 2000b: Interannual and interdecadal variations of the East Asian summer monsoon and tropical Pacific SSTs. Part II: Meridional structure of the monsoon. $J$. Climate, 13, 4326-4340.

Chao, Y., M. Ghil, and J.C. McWilliams, 2000: Pacific interdecadal variability in this century's sea surface temperatures. Geophy. Res. Lett., 27, 2261-2264.

Cholaw, B., L.-R. Ji, S.-Q. Sun, and M.-C. Cui, 2001: EAWM-related air-sea-land interaction and the Asian summer monsoon circulation. $A d v$. Atmos. Sci., 18, 659-673.

Huang, R. and Y. Wu, 1989: The influence of ENSO on the summer climate change in China and its mechanism. Adv. Atmos. Sci., 6, 21-32.

—, R. Zhang, and Q. Zhang, 2000: The 1997/98 ENSO cycle and its impact on summer climate anomalies in East Asia. Adv. Atmos. Sci., 17, 348-362.

Kalnay, E., M. Kanamitsu, R. Kistler, W. Collins, D. Deaven, L. Gandin, M. Iredall, S. Saha, G. White, J. Woolen, Y. Zhu, M. Chelliah, W. Ebisuzaki, W. Higgins, J. Janowiak, K.C. Mo, C. Ropelewski, J. Wang, A. Leetmaa, R. Reynolds, R. Jenne, and D. Joseph, 1996: The NCEP/ NCAR 40-year reanalysis project. Bull. Amer. Meteor. Soc., 77, 437-471.

Kawamura, R., 1998: A possible mechanism of the Asian summer monsoon-ENSO coupling. $J$. Meteor. Soc. Japan, 76, 1009-1027.
T. Matsuura, and S. Iizuka, 2001: Interannual atmosphere-ocean variations in the tropical western North Pacific relevant to the Asian summer monsoon-ENSO coupling. J. Meteor. Soc. Japan, 79, 883-898.

Krishnan, R. and M. Sugi, 2001: Baiu rainfall variability and associated monsoon teleconnections. J. Meteor. Soc. Japan, 79, 851-860.

Lau, K.-M., K.-M. Kim, and S. Yang, 2000: Dynamical and boundary forcing characteristics of regional components of the Asian summer monsoon. J. Climate, 13, 2461-2482.

and H.-Y. Weng, 1999: Interannual, decadalto-interdecadal and global warming signals in sea surface temperature during 1955-1997. J. Climate, 12, 1257-1267.

Luo, J.J. and T. Yamagata, 2001: Long-term El NiñoSouthern Oscillation (ENSO)-like variation with special emphasis on the South Pacific. $J$. Geophy. Res.-Oceans, 106, 22211-22227.

Mantua, N.J., S.R. Hare, Y. Zhang, J.M. Wallace, and R.C. Francis. 1997: A Pacific interdecadal climate oscillation with impacts on salmon production. Bull. Amer. Meteor. Soc., 78, 10691080.

Meehl, G.A., R. Lukas, G.N. Kiladis, K.M. Weickmann, A.J. Mattews, and M. Wheeler, 2001: A conceptual framework for time and space scale interactions in the climate system. Clim. Dyn., 17, 753-775.

Mitchell, T.P. and J.M. Wallace, 1996: ENSO seasonality: 1950-78 versus 1979-92. J. Climate, 9, 3149-3161.

Ninomiya, K., 1999: Moisture balance over China and the South China Sea during the summer monsoon in 1991 in relation to the intense rainfalls over China. J. Meteor. Soc. Japan, 77, 737-751.

Nitta, T. and Z.-Z. Hu, 1996: Summer climate variability in China and its association with $500 \mathrm{hPa}$ height and tropical convection. J. $\mathrm{Me}$ teor. Soc. Japan, 74, 425-445.

and S. Yamada, 1989: Recent warming of tropical sea surface temperature and its relationship to the Northern Hemisphere circulation. J. Meteor. Soc. Japan, 67, 375-383.

North, G.R., T.L. Bell, R.E. Cahalan, and E.J. Moeng, 1982: Sampling errors in estimation of empirical orthogonal functions. Mon. Wea. Rev., 110, 699-706.

Samel, A.N., W.-C. Wang, and X.-Z. Liang, 1999: The monsoon rainband over China and relationships with the Eurasian circulation. J. Climate, 12, 115-131.

Shen, X.-S., M. Kimoto, and A. Sumi, 1998: Role of land surface processes associated with interannual variability of broad-scale Asian sum- 
mer monsoon as simulated by the CCSR/NIES AGCM. J. Meteor. Soc. Japan, 76, 217-236.

Suga, T., A. Kato, and K. Hanawa, 2000: North Pacific tropical water: its climatology and temporal changes associated with the climate regime shift in the 1970s. Prog. Oceanography, 47, $223-256$.

Trenberth, K. and J.W. Hurrell, 1994: Decadal atmosphere-ocean variations in the Pacific. Clim. Dyn., 9, 303-319.

Wallace, J.M., C. Smith, and C.S. Bretherton, 1992: Singular value decomposition of wintertime sea surface temperature and 500-mb height anomalies. J. Climate, 5, 561-576.

Wang, S.-W., Z.-C. Zhao, Z.-H. Chen, and Z.-X. Tang, 1987: Drought/flood variations for the two thousand years in east China and comparison with global climatic change. In The Climate of China and Global Climate, D.-Z. Ye et al. eds, Beijing, China Ocean Press, 20-29.

Weng, H.-Y., K.-M. Lau, and Y.-K. Xue, 1999: Multiscale summer rainfall variability over China and its long-term link to global sea surface temperature variability. J. Meteor. Soc. Japan, 77, 845-857.

Wu, G.-X. and H.-Z. Liu, 1995: Neighborhood response of rainfall to tropical sea surface temperature anomalies. Part I. Numerical experiment. Chinese J. Atmos. Sci., 19, 279-292.

Yang, H., 2001: Anomalous atmospheric circulation, heat sources and moisture sinks in relation to great precipitation anomalies in the Yangtze River valley. Adv. Atmos. Sci., 18, 972-983.

Zhao, Z.-G., 1997: The major factors influencing on summer rainfall in China. Proceeding of the Twenty Second Annual Climate Diagnostic and Prediction Workshop. E.O. Lawrence Berkley National Laboratory, Univ. Calif., USA, 285288.

, 2001: Analysis of the factors influencing China's summer rainfall. Chapter 11 of the Advances in the contemporary climate research, Wang, S.-W. et al., eds. Meteorological Press, Beijing, China, pp. 458 (in Chinese). 